\title{
LA FORMACIÓN INTEGRAL. MITO Y REALIDAD
}

\section{Luis Enrique Orozco Silva*}

El que no puede lo que quiere, que quiera lo que puede.

\section{Introducción}

El ser y el hacer de la Universidad como institución que

satisface las necesidades de profesionalización de los países, como espacio de m e jor a miento de

1 o s niveles de cul$\mathrm{t} \mathrm{ur}$ a general de la p obla ción y como ins-

\section{(Leonardo)}

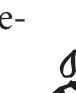

00

tancia de formación de una elite para

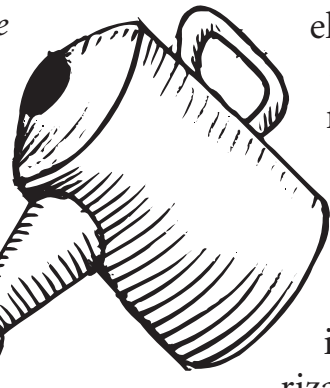

el desarrollo de la ciencia y la tecnología, requiere ser replanteado en el marco de los nuevos escenarios que afectan la efectividad de las instituciones, caracterizados por la globalidad, la movilidad, la flexibilidad, la complejidad y el impacto de la revolución científico-técnica en los modos de producción del conocimiento, en las dinámicas de aprendizaje y en la forma de relacionar las funciones sustantivas de las instituciones de educación superior. Los componentes tradicionales del concepto de universidad, aquellos que hacen parte de su historia milenaria, necesitan una interpretación que concilie la "idea de universidad" que forjaron los clásicos del pensamiento universitario, con las demandas actuales de sociedades que se asoman al próximo milenio sin haber resuelto su problema estructural de inequidad en la distribución de los bienes, con las

* Asesor de las Instituciones Salesianas de Educación Superior (IUS). Docente de la Universidad de los Andes-Colombia. 
consecuencias que de ello se derivan para las formas de organización de la sociedad, para sus estructuras jurídico-políticas y las diversas formas de la conciencia social. La Universidad como espacio de investigación, de formación humana y de apoyo solidario a la sociedad global puede seguir teniendo vigencia si, más allá de sus enunciados retóricos, se logra convertir tales funciones en propósitos precisos.

Uno de los objetivos finales de la institución universitaria consiste en brindar, además de la capacitación profesional, la formación del talento humano en dos direcciones básicas: la formación del carácter y de la personalidad del estudiante y el desarrollo de su pensamiento crítico. Dicho de otra manera: hacer posible su desarrollo moral y reflexivo como dimensiones del proceso de formación del ser humano.
La globalización y sus efectos en la cultura tanto como la incertidumbre sobre los criterios morales que deben orientar la vida social y el comportamiento individual en una sociedad del conocimiento se unen a la aparente inseguridad de las instituciones para definir de modo proactivo sus tareas prioritarias. En este contexto, los diagnósticos que sirven como base para redefinir las funciones y tareas de las instituciones abundan ${ }^{1}$ y es evidente la incoherencia e insuficiencia de las propuestas, provisionales o no, que se ofrecen. En esta, por lo menos, aparente confusión vale la pena volver sobre el tema de la formación integral como tópica que aglutina las tareas de toda institución universitaria: formar de modo integral el talento humano.

En el texto que sigue haremos referencia a esta dimensión central del quehacer universitario. Se desea abrir

1 Hernando Gómez Buendía et al. (director) Educación. La Agenda del Siglo XXI. Programa de Naciones Unidas para el Desarrollo. PNUD/TM ed. Bogotá, 1998. Ávalos, Beatrice. Caminando hacia el Siglo XXI. Docentes y procesos educativos en la Región Latinoamericana y del Caribe en: Boletín del Proyecto Principal de Educación en América Latina y el Caribe, N.41, UNESCO-OREALC, Santiago de Chile, 1996. Brunner J. Joaquín. Educación Superior en América Latina: una agenda para el año 2000. Universidad Nacional-IEPRI, Bogotá, 1995. Brunner J. Joaquín, Educación Superior en América Latina: cambios y desafíos. FCE Chile, 1990. Carmen García Guadilla, Situación y principales dinámicas de transformación en la Educación Superior. Cátedra UNESCO de la Universidad de los Andes, ed. CRESALC-UNESCO. Col. Respuestas, Caracas, 1996. Kent, Rollin (Comp.) Los temas críticos de la Educación Superior en América Latina, Estudios comparativos, FCE. Flacso-Universidad Autónoma de Aguas Calientes, México, 1996. Luis Enrique Orozco Silva, Universidad, Modernidad y Desarrollo Humano, UNESCO-CRESALC, Caracas, 1994. Carlos Tunnermann, La Educación Superior en el umbral del S. XXI, ed. CRESALC-UNESCO. Caracas 1996. UNESCO, Comisión Internacional de Educación para el Siglo XXI, Comisión Delors, París, 1995. Banco Mundial, La enseñanza Superior, Lecciones derivadas de la experiencia, Washington. D.C. 1995. 
espacios que permitan incrementar una reflexión sobre la universidad y sus tareas con conciencia de los desafíos actuales y, a su vez, contribuir a la discusión sobre el tema, más allá de los recintos universitarios, en el sector educativo en general.

\section{El Problema}

Se partirá del reconocimiento que siempre ha hecho la institución universitaria de su responsabilidad como instancia de formación del carácter y de la personalidad del estudiante y de su pensamiento crítico. Para cumplir con esta tarea cada institución ha desarrollado esfuerzos significativos sirviéndose para ello de diferentes modalidades: el aprendizaje de los idiomas clásicos y la filología; la docencia de la filosofía y de las letras; $y$, en los últimos tiempos, ofreciendo un conocimiento de las ciencias naturales, pero sobre todo de temas propios de las ciencias sociales. Se ha trabajado bajo el presupuesto de que el conocimiento del latín, del griego, o la lectura de los clásicos o el reconocimiento intelectual de los hechos históricos o sociales, o una mejor visión del universo físico complementa la capacitación profesional, logrando así una persona estructurada, de recio carácter, líder social y responsable frente a los otros.

Sin embargo, y a pesar de los esfuerzos realizados, se mantienen situaciones muy críticas en el entorno y contrarias al ideal buscado. La situación de injusticia generalizada, la violencia y la corrupción interrogan de alguna manera el tipo de formación que brinda la universidad en la medida en que es ella, en parte, la forjadora del talante moral y de la personalidad de sus egresados y, por su influencia en la socialización secundaria del individuo. Los estudiantes ingresan a la universidad con limitaciones relacionadas con el manejo de la lengua materna, con la capacidad para inducir y deducir para aprender en términos de proceso y con marcada preferencia por el aprendizaje del dato aislado, sin contexto alguno. Limitaciones, todas ellas significativas, para el logro de un pensamiento crítico. De esta manera, nos enfrentamos al siguiente hecho: el aporte que hace la universidad al desarrollo ético y crítico de los estudiantes está comprometido.

Podría suceder, dicen algunos, que el problema está en los medios utilizados para cumplir con esta tarea. Ahora bien, si se observan estos medios con cuidado se observa en ellos ciertas características comunes, a saber: 
- Medios de alcance limitado. Con los medios utilizados se logró un mayor conocimiento en el campo de las disciplinas referidas al área de la cultura y una cierta ampliación de la cosmovisión del estudiante, pero con una incidencia precaria -salvo contadas excepciones- en la adquisición o modificación de actitudes, en el desarrollo de la conciencia moral, en la posibilidad de asumir o modificar valores y en la adquisición de un pensamiento crítico. Quizá no se tuvo en cuenta que una cosa es el aprendizaje intelectual y otra el despliegue creativo de una voluntad libre; que el desarrollo cognitivo no lleva consigo el crecimiento moral; que en el aprendizaje técnico, inclusive, de las ciencias humanas y de la filosofía puede perderse la posibilidad que brindan de que el individuo se encuentre consigo mismo en los asuntos que analiza.

- El teoricismo acentuado y consistente en la transmisión descontextualizada de las humanidades o en el enfoque positivista en la enseñanza de las ciencias impidió, en algunos casos, que el estudiante viera en sus contenidos el producto de la acción humana susceptible, en consecuencia, no sólo de ser conocido sino criticado, modificado o re-creado de nuevo. A su vez, tal teoricismo impidió que el estudiante adquiriera una conciencia crítica frente al presente y un deseo de utopías frente al porvenir. Como posición intelectual, éste coincide bastante con el objetivismo derivado de las posiciones positivistas en las ciencias sociales. Uno y otro, aunque provengan de vertientes distintas, comparten un mismo espíritu: desligar la teoría de la práctica, esquivando que la persona reconozca sus ataduras sociales y los presupuestos ideológicos, metodológicos y teóricos de toda disciplina.

- El perfil de los docentes. Estos aspectos mencionados estuvieron relacionados con la formación de los docentes y con las metodologías de enseñanza utilizadas. En la mayoría de los casos el estudiante no fue expuesto a los "textos fuentes", en el caso del estudio de la filosofía o de las letras; o a los problemas reales, en el terreno de las ciencias sociales; o al testi- 
monio de una experiencia intelectual del docente, en los cursos profesionales; o a la discusión sobre la significación cultural de los conocimientos, en los variados campos de la ciencia o de las disciplinas humanísticas. De esta manera, el aprendizaje memorístico de fechas, de títulos de obras, de autores o personajes oscureció la posibilidad de un aprendizaje viviente y motivante por parte del estudiante.

- Ciencias versus humanidades. La existencia de una doble cultura (ciencias de la naturaleza - ciencias humanas) ha incidido, de igual manera, en una cierta escisión en los procesos de formación. Se desconoció con frecuencia que las ciencias forman parte de la cultura, no habiendo fundamento para separarlas, $y$ que mostrar la significación histórica, cultural y ética del desarrollo de la ciencia o de la técnica es tan humanístico como la docencia no adocenada de los clásicos en el terreno de las humanidades, del arte o de la filosofía.

- La oposición entre lo racional y lo humanístico. Con demasiada frecuencia, en el medio acadé- mico se ha sido prisionero de una distinción cuyo efecto se vuelve un obstáculo en la reflexión sobre las humanidades. Se trata de la oposición entre lo humanístico y lo racional. Sucede, de facto, como si el aprecio por las humanidades llevara consigo el menosprecio por la razón. Se olvida, como lo señala Savater, que "no hay humanidades sin respeto por lo racional, sin fundamentación racional a través de la controversia de lo que debe ser respetado y preferido". Sólo desde la perspectiva de la razón y su despliegue recibe fundamentación el espacio de lo práctico, espacio en el que se inscribe el interés por lo humanístico y su valor formativo. A su vez, sólo desde la razón se hace pensable lo intuitivo, la imaginación, lo psicoafectivo y la dimensión religiosa del hombre. La oposición entre lo racional y lo humanístico es sólo aparente.

- La autoimagen institucional y el entorno social. Estrecha, sin duda, fue la relación entre este tipo de prácticas en materia de formación y la imagen que de sí misma tenía la Universidad en cada momento de su historia. 
No es producto del azar que de la misma manera que la Universidad evolucionara, de su etapa colonial a la incipiente modernización de la primera mitad de este siglo, y de aquí a las últimas décadas (caracterizadas, en lo que se refiere al sistema de la educación superior, por la masificación de la matrícula, de las instituciones, de los programas, de los docentes y por la estratificación de las instituciones), la dimensión formativa tomará en cada momento el rostro de la misma institución; rostro que no era ajeno a la evolución de la dinámica social global en cuyo entramado la institución universitaria ha cumplido una finalidad específica que ha ido oscilando de una función primariamente ideológica, en la época colonial, a otra marcadamente economicista en el presente ${ }^{2}$. Más que fiel a su idea, quizá, la Universidad ha sido funcional a los estilos de desarrollo; más que formación, ha hecho capacitación de la fuerza de trabajo requerida, en el marco de un mercado de trabajo conspicuo y diversificado que no siempre se pone en tela de juicio. Quizá se ha vista a sí misma más como institución que imparte instrucción que como espacio de formación integral. Posición que puede llegar a ser correcta cuando se trata de un centro de capacitación profesional, pero que se torna crítica al tratarse de una institución universitaria que brinda educación "superior". "Para que la Universidad pueda desarrollar un programa de formación integral efectivo y que en verdad abra la conciencia estudiantil a campos esenciales de la experiencia humana, es necesario que esos campos de la cultura estén fuertemente representados en sus profesores, sus programas, sus materiales y recursos académicos, y en la calidad y el número de las investigaciones y publicaciones" 3

- Fuentes intelectuales de la docencia de las humanidades. En el marco de la problemática de la

2 Ricardo Lucio. ¿Qué tan Universidad es nuestra Universidad? Universidad de los Andes. Bogotá, enero de 1998.

3 Francisco Pizano de Brigard. Una Visión de la Universidad. Universidad de los Andes. 50 años. 1998. p.53 
formación brindada por las instituciones de educación superior es imposible no hacer una referencia, así sea esquemática, a la docencia de las humanidades y sus mediaciones intelectuales. Aunque la situación es similar en diferentes países, el caso de Colombia podrá iluminar esta dimensión del problema. Para tal efecto podemos poner de relieve las más significativas con el fin de tener un cuadro muy general de la orientación intelectual que se ha tenido y se tiene actualmente, sin excluir otras que el lector atento pueda identificar ${ }^{4}$. Ante todo, podemos reconocer una idea generalizada en todas las modalidades, a saber: que la formación se obtiene a través del conocimiento de las disciplinas denominadas humanidades $^{5}$. Esta idea, hoy puesta en tela de juicio, ha conducido en el plano organizacional de la universidad a asignar tal responsabilidad a las unidades académicas o departamentos de humanidades. Estos saberes -se cree- deben ofrecer al estudiante una imagen de sí mismos, de la vida, del mundo en que viven, y dotarlos de una capacidad de juicio para asumir con responsabilidad un puesto en la sociedad. La carencia de estos elementos en la personalidad del egresado se constituye en argumento mudo contra la eficacia, no de la universidad global, sino de los departamentos de humanidades.

Rafael Rivas Sacconi, El Latín en Colombia, Instituto Caro y Cuervo, Bogotá, 1993, Caps. I-II, pp. 41 y ss.

5 Respecto de las humanidades debe hacerse hacer una aclaración cuya presentación en detalle no es del caso en este texto: su origen primero lo encontramos, como lo muestra G. Jaeger, en su Paideia, en el pensamiento de los Sofistas (S.V A.C). En el mundo moderno, las humanidades o los estudios humanísticos resurgen de una disposición laica y no significó para la época, que hubiere textos humanos y otros menos humanos. En los albores de la modernidad se volvió a los clásicos para anteponerlos a los libros revelados. El latín y el griego se tornaron paradigmas como medio para volver a la fuente y fijar posiciones con contenidos no derivados de la fe, frente a otras posiciones menos laicas. Sin embargo, como lo señala Fernando Savater, el concepto de las humanidades ha estado sometido a variaciones históricas y condicionamientos sociales. Para unos, señala el autor, inicialmente formaron parte de las humanidades los Elementos de Geometría de Euclides tanto como los Diálogos de Platón. Para otros, más adelante, el estudio del griego y del latín fue importante, pero su compra, demasiado costosa (Rabelais). Otros pensaron que más que el conocimiento de los textos clásicos, era urgente saber pensar correctamente y comunicarse (Dukheim). Este mismo sugirió que lo más importante era vivir y que ello no exigía per se saber hablar con elegancia. 


\section{Corriente humanística-filológica}

El humanismo entró al país con los conquistadores y como un reflejo de la sociedad europea del siglo XVI. El eje de tal humanismo ha variado con el tiempo desde la primera escuela de latinidad, que se inauguró en Santafé en 1563, en el convento de la Orden de Santo Domingo a la que acudían los hijos de los conquistadores y pobladores del reino, hasta entrado el presente siglo. En cada momento sobresalieron figuras tales como Fernando Fernández de Valenzuela y Fray Andrés de San Nicolás, Mariano del Campo Larraondo, Miguel Antonio Caro, Baldonero Sanín Cano, Felix Restrepo. S.J. o Manuél Briceño S.J. para citar sólo algunos especialmente significativos en el culto del latín. Esta tendencia humanística-filológica tuvo como centro el estudio de los clásicos, la cultura helenística (en menor grado) y la filología. En ella se comprometieron historiadores, filólogos y políticos, y fueron ellos quienes proyectaron la imagen de una Colombia "Atenas suramericana" y "República de letras". De tal influencia provienen la Academia de la Lengua, el Instituto Caro y Cuervo y, quizá en la actualidad, los programas de filología e idiomas.

\section{Corriente humanístico-filosófica}

Sus antecedentes se encuentran sin duda alguna en la universidad colonial. Tuvo como espacio propio las facultadas de filosofía, y su predominio en la primera mitad del siglo XX. Para entonces, el concepto de humanidades que predominaba era el del Renacimiento, de corte laico y liberal, producto de la ruptura entre la Universitas del medioevo de corte católico y el libre, individual y secular de principios de la modernidad europea. Salvo en las universidades confesionales, este antagonismo entre humanismo cristiano y laicoliberal no llegó a ser tan antagónico que no pudieran coexistir con predominancia de uno de ellos. Máxime, cuando con el correr del tiempo fueron desapareciendo los especialistas para ser reemplazados por "aprendices de oficio". Paulatinamente, el espectro de esta corriente se fue abriendo para albergar los estudios de literatura y de lingüística modernas tal y como los conocemos hoy. Las filosofías que animaron este proceso fueron entre otras el utilitarismo de Bentham en la ética y la teoría de la jurisprudencia; el sensualismo de Destutt de Tracy en la teoría del conocimiento; el positivismo spenceriano en las personas de Nicolás Pinzón, Herrera Olarte y J.D. Herrera 
Iregui (hacia 1870), sin olvidar la gran influencia que la escolástica ejerció desde la colonia hasta bien entrado el siglo XX; el neotomismo; el existencialismo; el marxismo y el estructuralismo, en lo que va corriendo de este siglo, y las corrientes postmodernas en la filosofía, en la literatura y en las artes, en la actualidad.

Si bien se debe reconocer el papel positivo desempeñado por estas corrientes de pensamiento a lo largo de la vida cultural de la nación, también se debe hacer otro reconocimiento: el humanismo renacentista y aún aquel que le sucedió a principios del siglo impulsado por Ferdinand Canning, Schott Schiler, profesor este último, de Oxford, han perdido vigencia, su función en la universidad es secundaria y su preeminencia es simbólica, poco efectiva y, por qué no decirlo, decorativa. Maiz Vallenilla llega inclusive a pensar que: "si quienes nos dedicamos a estas disciplinas no tratamos de engañarnos, se impone una confesión y es la siguiente: dentro de la institución universitaria contemporánea las humanidades han cedido su puesto preeminente a la ciencia, e incluso (seamos aún más duros al decirlo) frente al ingente desarrollo y atracción que ejercen los estudios propios de la técnica". Se acabó la formación de los espíritus a través de "les belles lettres".

La razón de ser de las modificaciones en los contenidos debe buscarse, en parte, en la evolución social; en la medida en que el país fue dejando de ser una sociedad agraria $\mathrm{y}$ tradicional y fue avanzando en procesos de modernización, las humanidades clásicas se hicieron insuficientes como instrumentos de formación de la conciencia colectiva. La racionalidad científico-tecnológica encuentra hoy en su enfoque tradicional un escollo y comienza a generar desde el interior de sí misma una "imagen del hombre" que, proyectada como conciencia colectiva, sólo requiere para su crecimiento de un dominio instrumental del mundo.

Algunas universidades se niegan a hacer este reconocimiento y siguen añorando con nostalgia su "paraíso perdido". Para otras, por el contrario, significa el mayor desafío que se tiene en el presente, de recuperar el sentido humanístico que tiene el aprendizaje metódico de toda disciplina teórica o práctica y la apropiación crítica de la técnica.

\section{Las Ciencias Sociales como Humanidades}

Frente al cuestionamiento radical a las humanidades clásicas se ha pen- 
sado en una salida consistente en cumplir, a través de las ciencias sociales, con la función asignada a las humanidades. De esta manera, se encuentra en la mayoría de los programas de humanidades cursos de historia y de ciencias sociales. La historia, como la economía o la sociología han servido de apoyo a la tarea de la formación. Y lo han hecho a través del estudio de temas específicos para incentivar en los estudiantes un mejor conocimiento del entorno social y despertar algunas vocaciones hacia el estudio de las ciencias sociales. Se tiene la impresión de haber obtenido con ello un doble fin, fortalecer la presencia de las ciencias sociales en la universidad y hacer de las "humanidades" "algo más útil, interesante y complementario de los currículos profesionales". De igual manera, abriendo en los planes de estudio la posibilidad de ver materias optativas, los estudiantes han podido estudiar otras disciplinas distintas a aquellas que corresponden a su capacitación profesional; con frecuencia esta medida se legitima desde la necesidad sentida de disponer de planes de estudio flexibles y abiertos a la interdisciplinariedad. En la mayoría de los casos, esta última no se logra, por cuanto involucra una interacción teórico-metodológica entre las disciplinas, que la yuxtaposición de campos disciplinarios no satisface.

Quizá ha sido de mayor incidencia en la formación de los estudiantes, tener la posibilidad de vincularse con el mundo real en algún momento de su paso por la universidad a través de prácticas profesionales o de organizaciones estudiantiles específicamente pensadas para ello; en la medida en que esta experiencia, a juicio de los mismos estudiantes, los coloca en la realidad del país y les permite descubrir el "verdadero país", incitando en ellos la autoreflexión sobre su responsabilidad social en el futuro inmediato.

Si se mira en perspectiva estas tendencias, se puede decir que el latín, la filología, las humanidades (en su acepción renacentista) y en el presente, las ciencias sociales y diferentes modalidades de intervención de los estudiantes en el entorno real, han sido las mediaciones a través de las cuales la universidad ha buscado cumplir con su función formativa y cultural.

La situación actual parece crítica por cuanto no se reconoce en muchos sectores la crisis de legitimación de las humanidades clásicas, lo que impide su recuperación necesaria; y de otra parte, porque la absorción, 
por parte de las unidades académicas responsables del sector de humanidades, de los contenidos propios de las ciencias sociales genera, con frecuencia, un tratamiento no profesional de los problemas y, en consecuencia, trae consigo un bajo nivel de rendimiento académico en estos campos; así las cosas, los denominados "cursos costura" aumentan, disminuyendo al máximo su función formativa. Parecería entonces necesario que la función formativa de la institución universitaria deba ser replanteada sobre una nueva base, dados la limitación de los medios utilizados, la crisis del enfoque, los nuevos desafíos que la sociedad le impone a la universidad y la evolución que de hecho han tenido las humanidades como medio (medium) formativo dentro de la universidad.

\section{Las matemáticas, las ciencias naturales y la formación de los estu- diantes}

Desde los sofistas se ha descubierto el papel formativo de las matemáticas, para la época se les consideró como una gimnasia del entendimiento que podría ser muy útil como propedéutica de la filosofía. Su valor formativo fue especialmente puesto de relieve por Hipias. Esta disciplina formó parte relevante entre las siete artes liberales: gramática, dialéctica, retórica, aritmética, geometría, música y astronomía. Naturalmente, para los enemigos de los sofistas, la utilidad no era clara. Isócrates llegó a pensar - según lo narra Jaeger - en su Paideia, que las matemáticas eran un simple medio de educación formal del entendimiento. Pero los sofistas (Hipias) consideraban que su valor formativo radicaba en su naturaleza estrictamente teórica, en el potencial que en ellas apreciaban para el desarrollo de aptitudes distintas a las puramente técnicas. Lo que no estaba claro para los sofistas, ni para Platón y Aristóteles fue hasta qué punto debían extenderse estos estudios. Es importante recuperar la idea del alto potencial formativo de la ciencia puesto de relieve desde los tiempos de la formación ática. A ello contribuyeron ampliamente los sofistas (Hipias, Antifón) y los pitagóricos. No se puede poner en duda, desde entonces, el valor pedagógico de la ciencia aunque no se acierte a precisar cómo hacer el mejor uso de ella. Bajo esta intuición o reconocimiento, cada vez más en el contenido de la enseñanza de las humanidades se le otorga un lugar a las matemáticas, física y biología, principalmente. El predominio de la racionalidad científica y de la técnica ha venido demostrando su utilidad práctica y 
hacia el futuro estamos en la situación opuesta de los sofistas; el analfabetismo en ciencias básicas preocupa a gobernantes y educadores. No hay, sin embargo, una precisión respecto a la prioridad que deban recibir a la hora de definir una política de formación en las instituciones; como tampoco de su papel en la formación de un pensamiento crítico distinto, como lo veremos más adelante, del desarrollo de la inteligencia analítica.

\section{Los idiomas modernos y las huma- nidades}

Ningún fenómeno como la globalización actual, en cuanto ella significa una mayor interdependencia entre países y culturas obliga a considerar el manejo de otro idioma distinto del materno como un componente importante de la formación que puede brindar una institución de educación superior. En un mundo planetario la educación del individuo no puede ser provinciana. A su vez, la existencia de curricula universales en muchas carreras, tanto como la creciente movilidad académica y estudiantil obligan a las instituciones a vincular por fuerza de las cosas determinados idiomas a determinadas profesiones; y el predominio de diferentes áreas del globo en determinados mercados conlleva a que el idioma predominante en ellos se convierta en un factor de competitividad para los profesionales de hoy y del futuro. No hay en este caso, tampoco, una respuesta única respecto a los idiomas que deben privilegiarse, como tampoco la hay respecto a la orientación que debe seguirse en la enseñanza de un segundo o tercer idioma. Se oscila entre enseñar el idioma como un medio de comunicación o buscar que la persona penetre a través del dominio pleno del idioma en la cultura y la riqueza semántica que conlleva la apropiación de un "nuevo mundo" a través de la palabra y el lenguaje.

Pero parece que hay signos esperanzadores. Hoy, se vuelve cada vez con mayor preocupación sobre la tarea formativa de la universidad con el ánimo de subrayar la importancia de entenderla en su relación con la dimensión moral de los estudiantes y con el desarrollo de su pensamiento crítico; uno y otro aspecto deben considerarse sin perder de vista el contexto social. Inclusive, en varias instituciones se relaciona el cumplimiento de esta tarea con la naturaleza del acto educativo y con un concepto de lo social para evitar que la formación, como la educación de un pensamiento crítico, pueda ser reducida a una "técnica social".

En este contexto, que bien puede ser considerado como una nueva base de discusión del tema, la educa- 
ción es considerada como una praxis que tiene un sentido en sí misma. Esta no es entendida como una acción cuya finalidad le sea exterior bajo el modelo de la acción instrumental o técnica (téchne). Es, igualmente, apreciada como una acción orientada por un pensamiento, que posee, en consecuencia, un principio orientador y previo que le otorga sentido. A su vez, tiene un contenido (algo que se enseña) y un modus procedendi que singulariza y aúna el proceso del aprender por la mediación del maestro.

En este sentido, la práctica pedagógica es considerada como un proceso de transformación del sujeto que aprende y que posibilita poner en acto las posibilidades presentes virtualmente en él, con la ayuda del maestro, de unos contenidos y de unos procedimientos específicos. Esta es su naturaleza y finalidad propia; y porque ello tiene sentido para una sociedad que crece $y$ vale en cuanto crecen y valen quienes la componen, la educación recibe una "forma institucional" a la que se le asignan fines sociales que recoge la legislación, tales como: la protección y aprovechamiento de los recursos naturales; el conocimiento y reafirmación de los valores de la nacionalidad; la incorporación integral de los miembros de la sociedad a los beneficios del desarrollo científico y tecnológico. Beneficios encaminados a su perfeccionamiento personal y al desarrollo social y ético, entre otros. Aspectos que no tienen sentido sino como concreciones de los fines primeros del acto educativo ${ }^{6}$.

En la medida en que la Educación cumple con sus fines propios, forma el carácter y la personalidad del individuo, e incide en la personalidad en cuanto, como lo señala Kant, ésta última no es otra cosa que "la libertad e independencia respecto de los mecanismos de la naturaleza entera, considerada aquella al mismo tiempo, como poder de un ser sujeto a leyes puras, prácticas, que le son propias; es decir, dictadas por su propia razón. De manera que la persona perteneciente al mundo sensible está sujeta a su propia personalidad en cuanto pertenece también el mundo inteligible"7. La educación es, en consecuencia, educación en y para la 
libertad, fomenta el crecimiento de la persona y lo capacita para una vida útil y responsable frente a sí mismo y frente a la sociedad global.

En una palabra, la educación contribuye a la generación de espacios de eticidad en los que la vida humana se hace posible. Tales espacios constituyen el ámbito de lo humano y son la expresión del tipo de interacciones existentes entre los hombres.

A su vez, la sociedad es entendida como un conjunto de prácticas a través de las cuales la especie humana como el individuo buscan satisfacer su sistema histórico de necesidades a través del trabajo, el lenguaje y la interacción social. Prácticas, que se relacionan entre sí de manera no mecánica, que cubren los espacios propios de lo económico, lo sociocultural y político y que conforman la dinámica de toda formación social.

Entender la sociedad como praxis y al hombre como su expresión no mecánica permite poner de relieve la categoría de interacción como mediación constituyente (medium) de la subjetividad. En el principio era la acción. Pero esta práctica o praxis intencional y simbólica puede tener su fin (telos) en sí misma o no. En el primer caso, estamos hablando de acción instrumental de carácter estratégico, propia de todo quehacer técnico; en el segundo caso, se considera la acción por su valor propio más que por su eficacia externa en términos de la generación de un producto o la solución de un problema pragmático. En toda formación social se da uno y otro tipo de prácticas ${ }^{8}$.

No es pues arbitraria la relación que se establece entre Educación y Eticidad. Relación cuya sustancia es impensable sin lo social, entendido como interacción y sin una comprensión de las situaciones concretas en las que se define la existencia cotidiana. En algunos casos, la dificultad no radica en la comprensión teórica del problema sino en la determinación de una política apropiada que irrigue la institución como un todo y comprometa a los agentes educativos en su implementación.

\section{El concepto de formación}

Hans-Georg Gadamer, introduce el concepto de formación a propósito de una discusión sobre el estatuto metodológico de las ciencias humanas frente al de las ciencias de la naturaleza. El concepto de "forma- 
ción", dice el autor, fue sin duda alguna el más grande pensamiento del siglo XVIII, y el que designa el elemento en el que viven las ciencias del espíritu. Sin entrar en la discusión epistemológica, a continuación se va a seguir al autor en el desarrollo que brinda del concepto de "formación" (bildung). Desarrollo que se comparte en este texto y que permite entenderlo como "proceso por el que se adquiere cultura, y esta cultura misma en cuanto patrimonio personal del hombre culto", sin que se confunda cultura con el conjunto de realizaciones objetivas de una civilización, al margen de la personalidad del individuo. En forma breve, "formación" significa "ascenso a la humanidad"; desarrollo del hombre, en tanto hombre.

En su significación más inmediata el término hace referencia a "toda configuración producida por la naturaleza", como cuando se habla de la forma que tiene un terreno, o el tronco del árbol en su parte interna. Pero el término también puede utilizarse como sinónimo de cultura; como cuando decimos "hombre culto" u "hombre formado". En tal caso estaríamos significando: el modo específicamente humano de dar forma a las disposiciones y capacidades naturales del hombre.

En sentido más estricto, Kant en Cimentación para la Metafísica de las Costumbres ofrece un primer elemento para mostrar la significación estricta del término. Allí habla el autor de las obligaciones que se tienen consigo mismo; precisa entre ellas, la de no dejar oxidar los propios talentos. Pero no utiliza el término bildung. Es Hegel, al recoger esta idea de Kant, quien habla de formación y luego, W. Von Humboldt quien va a distinguir entre formación y cultura. Con formación, como lo señala Gadamer, se refiere a "algo más elevado y más interior; al modo de percibir que procede del conocimiento y del sentimiento de toda vida espiritual y ética y que se derrama armoniosamente sobre la sensibilidad y el carácter"9. La cultura, por su parte, no es desarrollo de capacidades y de talentos y, por lo tanto, se va más allá del planteamiento de Kant en la obra aludida, apuntando al despliegue del ser de la persona desde su interioridad. 
La idea de proceso puede ayudar a entender el concepto de formación formulado por Humboldt, inspirado en Hegel. En efecto, la formación hace referencia más al proceso de su obtención, que a ella misma como resultado. Esto significa que la formación como resultado no se produce como los objetos técnicos, sino que surge de un proceso interior, que se encuentra en un constante desarrollo y progresión. Los objetivos de la formación no son exteriores. Dicho de manera más radical, la formación no puede ser entendida como un objetivo. No es adecuado decir, por ejemplo: que la formación tiene como objetivo el desarrollo de una capacidad o de un talento. Gadamer precisa a este respecto: " en la formación uno se apropia por entero, aquello en lo cual y a través de lo cual uno se forma"10. En la formación como proceso todo lo que ella incorpora se integra en ella; pero lo incorporado no es como un medio que aparece, sino que todo se conser$v a$ ". Este conservarse nos indica que la formación "bildung" es un concepto histórico. De esta conservación $\mathrm{y}$ de sus modos es justamente de lo que tratan las ciencias humanas. El espíritu humano es "devenir" (llegar a ser). Esta frase conduce a la perspectiva de Hegel para entender el sentido del término en una forma dialéctica.

La característica primordial del ser humano es su ruptura con lo inmediato y natural; ruptura que le es propia en virtud de su opuesto que lo define: el ser espiritual y racional. De esta manera, no hay una coincidencia entre ser y deber ser en el caso del hombre. El hombre no es por naturaleza lo que debe ser. Justamente por ello necesita de formación; la esencia formal de la formación es elevarse a la generalidad; trascender la singularidad. En este sentido - según Hegel- la persona no formada es "aquella que no es capaz de apartar su atención de sí mismo y dirigirla a una generalidad desde la cual determinar su particularidad con consideración y medida" 11 .

Es importante precisar que para Hegel hay dos clases de formación. La primera de ellas es la formación práctica consistente en que el individuo se atribuye una generalidad. "El sacrificio de la particularidad signifi- 
ca negativamente inhibición del deseo y en consecuencia libertad respecto al objeto del mismo y libertad para su objetividad"12. En esta justa medida se fragua la autoconciencia verdaderamente libre en y para sí misma. En caso contrario, la conciencia enajenada, permanece fuera de sí (en lo otro) sin devenir ella misma como autoconciencia libre. Sólo así la conciencia trasciende la inmediatez del deseo, la necesidad personal y el interés privado, para devenir conciencia de sí. La formación teórica, por el contrario, consiste "en aprender a aceptar la validez de otras cosas y encontrar puntos de vista generales para aprehender la cosa, lo objetivo en su libertad, sin interés ni provecho propio"13.

Pero la formación integralmente considerada incluye una y otra formación, en un devenir del espíritu de su estado natural, hacia la libertad. La formación teórica es la continuación de un trabajo de formación que el hombre va incorporando en el proceso mismo en que incorpora el lenguaje y las costumbres: "cada individuo que asciende desde su ser natural hacia lo espiritual encuentra en el idioma, costumbres e instituciones de su pueblo una sustancia dada que debe hacer suya de un modo análogo a como adquiere el lenguaje. En este sentido el individuo se encuentra constantemente en el camino de la formación y de la superación de su naturalidad, ya que el mundo en el que ha entrado está conformado humanamente en el lenguaje y las costumbres" 14 .

Por lo tanto, se debe precisar que la generalidad a la que se eleva el individuo formado no es la generalidad abstracta de la razón, sino la generalidad concreta de una comunidad o de un pueblo específico. Se inscribe en el "mundo de la vida".

Pero la formación conlleva, a su vez, otras dimensiones que Gadamer subraya con el apoyo de los trabajos de Helmholtz sobre la sensibilidad o el tacto artístico. Con ello se alude a "una determinada sensibilidad y capacidad de percepción de situaciones, así como para el comportamiento dentro de ellas cuando no poseemos respecto a ellas ningún saber derivado de principios generales"15. En sentido contrario, no tener tacto sería expresar lo que puede evitarse. 
El tacto no consiste simplemente en la capacidad de servirse de una buena memoria para llegar a conocimientos no estrictamente evidentes, ni en una disposición o capacidad general; memoria no es memoria para todo, es siempre memoria de algo. A la memoria pertenece también el olvido. "El tacto ayuda a mantener la distancia, evita lo chocante, el acercamiento excesivo y la violación de la esfera íntima de la persona"; pero no es un problema de ética, es una manera de conocer y una manera de ser. "El que tiene sentido estético sabe separar lo bello de lo feo, la buena de la mala calidad, y el que tiene sentido histórico sabe lo que es posible y lo que no en un determinado momento, y tiene sensibilidad para tomar lo que distingue el pasado del presente" 16 .

La sensibiliddad histórica es sensibilidad frente al devenir de sí mismo, es sensibilidad frente a la realidad, como proceso siempre inacabado. Es también sensibilidad frente al inacabamiento de toda comprensión.

Pero no se trata de características adquiridas sino, más bien, de cualidades del ser en cuanto "formado"; en cuanto "de-venido". A esta sensibilidad estética e histórica no se llega por adiestramiento, ni con tácticas de aprendizaje. "La formación, agrega Gadamer, comprende un sentido general de la mesura y de la distancia respecto de sí mismo y, en esta misma medida, poder elevarse por encima de sí mismo hacia la generalidad"17. En cuanto la conciencia formada no es una propiedad del hombre en su estado natural, debemos decir que éste necesita formarse; y que en cuanto trasciende todo sentido natural (siempre limitado y determinado) y que en cuanto opera en todas las direcciones, se torna un sentido general.

Si la generalidad de la que se viene hablando tiene que ver con la realidad concreta e histórica de los pueblos y comunidades, deberá implicar también el logro del desarrollo del sentido común. Este aunque no es un saber por causas permite hallar lo verosimil. Se trata de un saber orientado a la situación concreta; no se confunde con la denominada capacidad de juicio; se sustrae al concepto racional de saber; en una palabra, se trata del saber denominado por Aristóteles de la phrónesis. Saber que permite acoger y dominar éticamente una situación concreta. Para Vico es "el sentido de lo justo y del 
bien común que vive en todos los hombres; más aún, es un sentido que se adquiere a través de la "comunidad de vida" y que es determinado por las ordenaciones y objetivos de ésta"18. No es un saber técnico que se oriente por principios objetivos; es un saber práctico que se orienta por principios generales hacia la situación concreta inmersa en sus circunstancias. No es un saber que se pueda enseñar porque es "énergie interieure d'une intelligence qui se reconquiert à tout moment sur elle même, éliminant les idées faites pour laisser la place libre aux idées que se font"19. Mientras los demás sentidos nos colocan en relación con cosas, el sentido común preside las relaciones con personas; se trata de una "especie de genio para la vida práctica”.

Pero también hace parte de la formación la capacidad de juicio y el gusto. La primera, en cuanto poder de subsumir lo particular dentro de lo general; capacidad estética de emitir juicios prácticos que orientan la vida; y el segundo, como capacidad de separarse de uno mismo y de sus intereses privados, hasta el punto de permitir que el individuo, bajo su preeminencia, pueda separarse de la moda con libertad y superioridad específicas.

A propósito del gusto, quizá valga la pena traer a cuento el comentario hecho por Gadamer sobre B. Gracián: "Su ideal de hombre culto (el discreto) consiste en que éste sea el hombre en punto, esto es, aquel que alcanza en todas las cosas de la vida y de la sociedad la justa libertad de la distancia, de modo que sepa distinguir y elegir con superioridad y conciencia" 20 .

Desde este perspectiva es fácil pensar en relación con la formación integral, por qué ésta debe permitir ligar los contenidos de la enseñanza a sus contenidos con su pasado, con su significación cultural, ética y estética, buscando fortalecer la capacidad humana de comunicación, de narración, de lectura y escritura frente al ruidoso vacío intelectual, por un lado, y a la retirada de la literatura hacia las vitrinas de los museos, por otro.

El desarrollo de la capacidad de narración es un medio de ayudar a que la persona pueda encontrar sentido a lo que hace, no en la cadena de relaciones causales sino en el espacio de lo práctico y mediante juicios que orientan la vida sin ser apodícticos; 
"La habilidad para construir narraciones y para entenderlos es crucial en la comprensión de nuestras vidas y la construcción de un "lugar" para nosotros mismos en el posible mundo al que nos enfrentemos". Evitar -al decir de Stirner- el "perfil argumental" chillón o la versión predigerida y trivializada de los clásicos, por un lado, y la ilegible edición anotada, por otro.

La ilustración debe luchar por recuperar entre estas posiciones señaladas el término medio. "Si no se consigue, si une lecture bien faite se convierte en un artificio con fecha de caducidad, nuestras vidas se verán invadidas por un gran vacío, y nunca más experimentaremos la tranquilidad y la luz del cuadro de Chardín"21. Quizá por eso en tal arte y en tal medio de formación la lectura de los grandes autores conduce hacia horizontes inusitados en el conocimiento de nosotros mismos.

\section{El concepto de Formación Integral}

Formación Integral es entonces aquella que contribuye a enriquecer el proceso de socialización del estudiante, que afina su sensibilidad mediante el desarrollo de sus facultades artísticas, contribuye a su desarrollo moral y abre su espíritu al pensamiento crítico $^{22}$. En este proceso, el estudiante se expone a la argumentación y contra-argumentación fundadas, a la experiencia estética en sus múltiples dimensiones y al desarrollo de sus aptitudes y actitudes morales, a través de experiencias que van estimulando y afinando su entendimiento y sensibilidad, tanto como su capacidad reflexiva y que en ello van "formando", en últimas, su persona.

La formación integral va más allá de la capacitación profesional aunque la incluye. Es un enfoque o forma de educar. La educación que brinda la universidad es integral en la medida en que enfoque a la persona del estudiante como una totalidad y que no lo considere únicamente en su potencial cognoscitivo o en su capacidad para el quehacer técnico o profesional. El ámbito de la formación integral es el de una práctica educativa centrada en la persona humana y orientada a cualificar su socializa-

21 George Steiner, Pasión Intacta, Ed. Siruela, Norma, Bogotá, 1997, p. 48.

Véase, igualmente: Jerome Brunner. La Educación, puerta de la cultura. Visor.

Dis. Madrid, 1997, Cap. 1. pp. 19-63.

22 J.G. Fichte. Discursos a la Nación Alemana. Ed. Nacional, Madrid, 1977, pp. 110 y ss. Véase, igualmente: Francisco Pizano de Brigard. Una Visión de la Universidad. Universidad de los Andes. 50 años. Santafé de Bogotá, 1998, p.15. 
ción para que el estudiante pueda desarrollar su capacidad de servirse en forma autónoma del potencial de su espíritu en el marco de la sociedad en que vive y pueda comprometerse con sentido histórico en su transformación ${ }^{23}$.

Al señalar la relación entre formación integral y socialización se desea subrayar el papel que juega la Universidad frente al estudiante como ente en el que éste último está expuesto a la experiencia de socialización secundaria. Si bien es cierto que la inducción amplia y coherente del estudiante en el mundo objetivo de su sociedad o de un sector de ella se realiza en su socialización primaria y que ésta constituye para cada quien la base para la construcción de su mundo en cuanto realidad significativa y social; no obstante, cualquier proceso posterior que induzca al individuo ya socializado a nuevos sectores del mundo objetivo debe ser tomado en cuenta, así como también los factores que en él intervienen: la afectividad y el lenguaje. En efecto, esta modalidad -como lo señalan Berger y Luckmann- en la que se adquiere el conocimiento específico de roles, requiere la adquisición de vocabularios específicos e implica, por lo tanto, la internalización de campos semánticos de rutina dentro de un área institucional, comprensiones tácitas, evaluaciones y coloraciones afectivas de estos campos semánticos y un aparato legitimador mediado por el lenguaje (no sólo como instrumento) en cuanto interiorización de imágenes y alegorías elaboradas desde la base de éste ${ }^{24}$.

En este sentido, la acción de una educación integral no permite la creación de un mundo subjetivo del estudiante partiendo de la nada ni es el único instrumento a través del cual la persona asume el mundo en que vive para modificarlo luego, ni mucho menos le posibilita adquirir una identidad personal por encima de la ya adquirida inicialmente. La educación obra sobre una interioridad pre-formada. Quizá por ello, la estrategia formativa consista en "familiarizar" al estudiante, es decir, en actuar "como si" aquellos valores que se desean inculcar pertenecieran a esa originaria y duradera experiencia de la vida que es el "hogar primero".

A su vez, sería conveniente que la acción de la Universidad, como espacio educativo, trabaje sobre las inco- 
herencias entre la socialización primaria y secundaria y sobre la base de la diversidad y heterogeneidad de socializaciones de los estudiantes. De aquí la importancia de que en la formación integral se generen procesos de identificación e inevitabilidad que acerquen la dinámica formativa a los procesos naturales de la socialización primaria.

Pero dada la diversidad de sistemas de identificación e inevitabilidad que se dan en el marco de una institución y en la sociedad global no parece posible tener una pauta única de formación.

Esto no significa que pierda vigencia el hecho, importante para evaluar, del impacto en la formación, del tipo de relación existente entre profesor-alumno en el proceso de aprendizaje; aquel, como todos los miembros de la comunidad universitaria pero de manera más incisiva, reafirma la estructura básica de la vida cotidiana, refuerza las coordenadas de la realidad del individuo y cumple un papel insustituible en el mantenimiento o cambio de la realidad con su testimonio personal frente a la ciencia, la moral o las costumbres vigentes.

De lo anterior se infiere que la institución universitaria contribuye a la formación humana de quienes pasan por ella en la medida en que a través de sus funciones de docencia, investigación y proyección hacia la sociedad involucra al estudiante en vivencias intelectuales, estéticas y morales que le permiten sentirse implicado y afectivamente comprometido en prácticas específicas y valores determinados. La universidad es espacio de un compromiso práctico y colectivo. Cuáles prácticas y cuáles valores adopte es un asunto que dependerá del rostro de la institución, y con él, de la manera en que ésta comprenda su sentido dentro de una sociedad determinada ${ }^{25}$.

$\mathrm{Al}$ decir que la Formación Integral compromete al quehacer universitario en su conjunto se está señalando que todos los niveles de la institución están involucrados en ella y permeados por sus fines: el profesor, el estudiante y el directivo de la universidad. En la interacción diaria se define el clima formativo, el "éthos universitario". Tal interacción define prácticas administrativas, docentes, investigativas, de relación humana en el interior de las cuales todos dan testimonio de su visión del "mundo de la vida" de la sociedad en que se vive, de las producciones del espíritu humano en general. En ellas, el estudiante y el 
profesor resultan esencialmente modificados; es decir, con cambios positivos o negativos- en su "forma". En la medida en que de tales interacciones salgan fortalecidos, "crecidos", con una "forma superior", se dice que se trata de una "experiencia formativa", o que se recibe una "educación superior" y para lo superior.

En este contexto, se ponen de relieve la dimensión simbólica del proceso de aprendizaje, la dimensión ética del manejo académico de los curricula y de las formas de evaluación del aprendizaje y la finalidad cultural y crítica de la Universidad en el desarrollo y la docencia de la ciencia. Los cursos que con destinación específica se ocupan de familiarizar a la persona del estudiante con los grandes valores de la cultura y sensibilizarlo ante la dimensión estética de la existencia cumplen la función de fortalecer y acrecentar el conocimiento, las actitudes y los valores pero no reemplazan la responsabilidad de todos en el quehacer de formación integral de la universidad. Su destino debería ser el de desaparecer en la medida en que el interés formativo esté presente en toda acción de quienes componen la Universidad. Un saber cualquiera -comprendido el de las humanidades- que se trasmite con carácter instrumental, ex- clusivamente, despoja al mismo de todo interés vital; es decir, de todo sentido humanístico.

Pero se es consciente de que no existen fórmulas para el logro de una formación integral de quienes pasan por la universidad. En la medida en que, como se ha señalado, aquella sea más un enfoque del quehacer de la institución que una práctica estratégica, el ideal de la formación integral servirá como "idea regulativa" que oriente la acción y no un concepto acabado susceptible de fórmulas de mecánica aplicación. Entre el mito y la realidad nos queda la difícil tarea de aceptar el reto de contribuir a la viabilidad de la sociedad a través de la formación integral de los futuros dirigentes.

\section{Bibliografía}

ADORNO, T.W.

$1970 \quad$ La Crítica de la Cultura y la Sociedad, en: Crítica cultural y sociedad, Ariel, Barcelona.

ADORNO, T.W.

1982 La Ideología como Lenguaje, Edit. Taurus, Madrid.

ADORNO, T.W.

1969 Consignas, Amorrortu Edit. México.

ÁVALOS, Beatrice

1996 Caminando hacia el S. XXI, Docentes y procesos educativos en la Región Latinoamericana y del Caribe, en Bole- 
Luis Enrique Orozco Silva

tín del Proyecto Principal de Educación en América Latina y el Caribe, No. 41, UNESCO-OREALC, Santiago de Chile.

APEL, Karl-Otto

1987 La transformación de la Filosofía, Edit. Taurus, Madrid.

\section{ARISTÓTELES}

1972 Ethique a Nicomaque, Edit. Jean Vrin, Paris.

ASCOMBE, G.E.M

1971 Introducción al "Tractatus" de Wittgenstein, Edit. Atheneo, Buenos Aires.

BOURDIEU, Pierre y Passeron, Jean

1970 La Réproduction, Éléments pour une théorie du systeme d'enseignement, Les Éditions de Minuit, Paris.

BRUNNER, J. Joaquín

1989 Un espejo trizado, FLACSO, Santiago de Chile, pp.187 y ss.

BRUNNER, J. Joaquín

1995 Educación Superior en América Latina: una agenda para el año 2.000, Universidad Nacional-IEPRI, Bogotá.

BRUNNER, J. Joaquín

1990 Educación Superior en América Latina: cambios y desafíos, F.C.E. Chile.

CORTINA, Adela

$1998 \quad$ El mundo de los valores, Edit. El Búho. Bogotá.

CORTINA, Adela

1986 Etica mínima, Edit. Tecnos, Madrid.

CORTINA, Adela

1990 Etica sin moral, Edit. Tecnos, Madrid.
CORTINA, Adela

1994 La ética de la sociedad civil, Anaya/Alauda, Madrid.

DELEUZE, Gilles

1977 Empirismo y subjetividad, Granica, Edit. Barcelona.

ELIOT, T.S.

1982 Notas para la definición de la cultura, Emecé Edit. Buenos Aires.

GARCIA GUADILLA, Carmen

1996 Situación y principales dinámicas de transformación en la educación superior. Cátedra UNESCO de Educación de la Universidad de los Andes, Bogotá. Ed. CRESALCUNESCO, Caracas.

FERRY, Jean Marc; HABERMAS, Jürgen

1987 L'Éthique de la Comunication, P.U.F., París.

Fichte, Schleiermacher, Humboldt, Nietsche, De Lagarde, Weber, Scheller

1959 La idea la Universidad en Alemania. Ed. Suramericana, Buenos Aires.

FREUD, Sigmund

1981 El Malestar en la cultura, en: Obras Completas, Vol. III, Biblioteca Nueva, Madrid.

GADAMER, Hans-Georg

1988 Verdad y método, Ediciones Sígueme, 2 Vols., Salamanca.

GÓMEZ BUENDÍA, Hernando (director)

1998 Educación, la agenda del S.XXI, PNUD / Tercer Mundo Editores, Bogotá.

HABERMAS, Jürgen

1987 Teoría de la acción comunicativa, Taurus, Madrid. 


\section{HABERMAS, Jürgen \\ 1979 Trabajo e interacción, en: ECO, No. 211, Bogotá, mayo. \\ HABERMAS, Jürgen \\ 1985 Conciencia moral y acción comunicativa, Edit. Penín- sula, Barcelona. \\ HABERMAS, Jürgen \\ 1985 Moralidad y costumbridad, \\ (Conferencia de 1985), en: Revista de la Universidad de Antioquia, (Trad. de Jorge Montoya Peláez). \\ HABERMAS, Jürgen \\ 1992 De l'étique de la discussión, Edit. CERF, París. \\ KANT, E. \\ 1971 Critique de la Raison Prati- que, P.U.F., Paris.}

KANT, E.

Fundamentación de la metafísica de las costumbres, Madrid.

KENT, Rollin (Comp.)

1996 Los temas críticos de la educación superior en América Latina. Estudios comparativos, F.C. E. FLACSO-Universidad Autónoma de Aguas Calientes, México.

KOHLBERG, L.

1984 La comunidad justa en el desarrollo moral, en: El sentido de lo humano. Valores, psicología y educación, Edit. Gazeta, Santafé de Bogotá.

KOLAKOWSKI, Leszek

Símbolos religiosos y cultura humanística, en Vigencia y caducidad de las tradiciones cristianas, Amorrortu Editores, pp. 89 y ss.
KÜNG, Hans

1990 Proyecto de una ética mundial, Edit. Trotta, Madrid.

MARCUSE, Herbert

1969 Para una teoría crítica de la sociedad, Tiempo Nuevo, Caracas.

OROZCO SILVA, Luis Enrique

1999 La Formación Integral, Mito y Realidad, Edit. Uniandes, Tercer Mundo, Bogotá, noviembre.

ORTEGA y GASSET, J.

1982 Misión de la Universidad, en: Revista de Occidente, (1930).

RAWLS, John

1990 Sobre las libertades, Barcelona, Edit. Paidós, Barcelona.

RORTY, R.

1996 Contingencia, ironía y solidaridad, Edit. Paidós, Barcelona.

SAVATER, Fernando

1997 El valor de educar, Ariel, Edit. Norma, Bogotá.

STEINER, George

1997 Pasión intacta, Edit. Norma, Bogotá.

STEINER George

1996 Antígonas, Edit. Gedisa, Barcelona.

TUNNERMANN B., Carlos

1998 En el umbral del siglo XXI. Desafíos para los educadores $y$ la educación superior, UNESCO, Panamá.

UNESCO

1995 Comisión Internacional de Educación para el siglo XXI, Comisión Delors, París. 
Luis Enrique Orozco Silva

VARELA B., Hilda

1985 Cultura y resistencia cultural. Una lectura política, Edit. El Caballito, México.
WEBER, Max

1967 La ciencia como vocación, en: Weber, Max, El político y el científico, Madrid. 